\title{
Investigating the Photocatalytic Degradation of Oil Paint using ATR-IR and AFM-IR
}

DOI:

10.1021/acsami.7b00638

\section{Document Version}

Accepted author manuscript

Link to publication record in Manchester Research Explorer

\section{Citation for published version (APA):}

Morsch, S., van Driel, B. A., van den Berg, K. J., \& Dik, J. (2017). Investigating the Photocatalytic Degradation of Oil Paint using ATR-IR and AFM-IR. ACS Applied Materials and Interfaces.

https://doi.org/10.1021/acsami.7b00638

\section{Published in:}

ACS Applied Materials and Interfaces

\section{Citing this paper}

Please note that where the full-text provided on Manchester Research Explorer is the Author Accepted Manuscript or Proof version this may differ from the final Published version. If citing, it is advised that you check and use the publisher's definitive version.

\section{General rights}

Copyright and moral rights for the publications made accessible in the Research Explorer are retained by the authors and/or other copyright owners and it is a condition of accessing publications that users recognise and abide by the legal requirements associated with these rights.

\section{Takedown policy}

If you believe that this document breaches copyright please refer to the University of Manchester's Takedown Procedures [http://man.ac.uk/04Y6Bo] or contact uml.scholarlycommunications@manchester.ac.uk providing relevant details, so we can investigate your claim.

\section{OPEN ACCESS}




\section{Investigating the Photocatalytic Degradation of Oil Paint using ATR-IR and AFM-IR}

Suzanne Morsch ${ }^{1 *}$, Birgit A. Van Driel ${ }^{2,3,4}$, Klaas J. Van den Berg ${ }^{3}$, Joris Dik ${ }^{4}$

${ }^{1}$ Corrosion and Protection Centre,

School of Materials,

The University of Manchester,

The Mill,

Sackville St,

Manchester, M13 9PL, UK

${ }^{2}$ Rijksmuseum,

Hobbemastraat 22,

1071 ZC Amsterdam, The Netherlands

${ }^{3}$ Cultural Heritage Agency of the Netherlands,

Hobbemastraat 22,

1071 ZC, Amsterdam, The Netherlands

${ }^{4}$ Materials for Arts and Archeology,

3ME, TU Delft,

Mekelweg 3,

2628 CD Delft, The Netherlands

\footnotetext{
${ }^{1}$ To whom correspondence should be addressed. Suzanne.morsch@manchester.ac.uk tel: +44 161 3062914
} 


\section{ABSTRACT}

As linseed oil has a longstanding and continuing history of use as a binder in artistic paints, developing an understanding of its degradation mechanism is critical to conservation efforts. At present, little can be done to detect the early stages of oil paint deterioration due to the complex chemical composition of degrading paints. In this work, we use advanced infrared analysis techniques to investigate the UVinduced deterioration of model linseed oil paints in detail. Sub-diffraction limit infrared analysis (AFM-IR) is applied to identify and map accelerated degradation in the presence of two different grades of titanium white pigment particles (rutile or anatase $\mathrm{TiO}_{2}$ ). Differentiation between the degradation of these two formulations demonstrates the sensitivity of this approach. The identification of characteristic peaks and transient species residing at the paint surface allows infrared absorbance peaks related to degradation deeper in the film to be extricated from conventional ATR-FTIR spectra, potentially opening up a new approach to degradation monitoring.

KEYWORDS: Linseed oil; titanium white; photocatalytic degradation; FTIR; AFM-IR. 


\section{Introduction}

Linseed oils have been used as a medium for oil paintings since medieval times, owing to their capacity to form reasonably stable, continuous films with good optical and mechanical properties. Nonetheless, paints made from these and other drying oils are susceptible to long-term degradation, leading to e.g. undesirable changes in optical appearance ${ }^{1,2}$. For conservation purposes, an in-depth understanding of these degradation mechanisms is necessary to design effective detection and prevention strategies. However, in common with other drying oils, defining the degradation process is notoriously problematic, since linseed oils are complex mixtures of naturally-derived triglyceride molecules based on fatty acids (primarily linolenic, linoleic, oleic, stearic and palmitic acids, with concentrations dependent on the source), Scheme 1. Numerous competing radical reactions drive cross-linking and chain scission, and furthermore, these processes can occur simultaneously. Therefore, no clear distinction can be made between drying and aging. $3,4,5,6$

A general mechanism for linseed oil hardening has nonetheless been established; it is widely accepted that oxidative curing is initiated by hydrogen abstraction from methylene groups adjacent to fatty acid cis alkenes (since the unsaturated bonds stabilise generated radicals by conjugation), Schemes 1 and 2 . Oxygen sorption then results in the formation of highly reactive peroxy radicals, followed by a variety of radical coupling reactions that ultimately lead to crosslinking. ${ }^{7}$ At the same time, chain-scission reactions are initiated by further radical formation (via e.g., B-scission reactions). Furthermore, in artists paint the complexity of this process is compounded by interaction with the inorganic pigments, which can affect both the drying process and the degradation kinetics. For example, pigments behaving as Lewis acids or bases locally induce metal salt or soap formation and may accelerate hydrolysis, $8,9,10,11,12,13,14$ whereas photocatalytic pigments, such as titanium white, can induce additional radical formation. ${ }^{15,16}$

Titanium white pigments were introduced in the beginning of the $20^{\text {th }}$ century, and paints containing these pigments have been used in many renowned artworks produced since (e.g., paintings by Picasso, Mondrian, and Pollock). These prevalent pigments occur in numerous forms, including the pure anatase and rutile polymorphs, with or without surface coatings. As a result, photocatalytic activity varies drastically. Generally, pure anatase exhibits the highest photocatalytic activity while rutile is considered more benign, and surface coatings further reduce activity ${ }^{17,18}$. Upon UV absorption, photocatalytic pigments provide reactive electrons at the surface of 
particles, resulting in the formation of organic radical and reactive oxygen species. For binders that cure by radical polymerization (e.g., linseed oil), the presence of photocatalytic pigments is therefore expected to accelerate crosslinking, and this may result in embrittlement. Concurrent degradation processes are also expected to initiate, and these ultimately manifest as chalking, where pigment powders are exposed at the paint surface after the binder has been broken down into volatile low molecular weight species ${ }^{16,19}$. Valuable works of art containing titanium dioxide are relatively recent and often stored under controlled conditions, therefore these longterm degradation effects are rarely observed ${ }^{20}$. Nonetheless, understanding the degradation mechanism is key to the development of prophylactic conservation strategies. It has recently been reported that uncoated anatase pigments dramatically accelerate UV-induced degradation of linseed oil when compared to coated rutile pigments. Surface sensitive techniques (AFM, XPS) were used to prove that the pigments were rapidly exposed at the paint surface, and that this was followed by visible chalking. However, little information about the binder degradation mechanism is provided by these techniques. ${ }^{16}$

One approach to polymeric analysis, infrared spectroscopy, can provide detailed information about the presence and chemical environment of functional groups, and has previously been used to investigate the drying and aging mechanisms of oil paints. ${ }^{7,11,21}$ However, conventional FTIR analysis is ordinarily confined to bulk measurements, where lateral resolution is restricted by the beam spot size and the penetration depth is dependent on the collection mode. Bulk spectra therefore represent an average of all chemical changes occurring within this sampling space. In contrast, the early stages of pigment-induced degradation are expected to be heterogeneous, involving highly localised chemical changes. To overcome this, FTIR microspectroscopy has previously been used to map aged paint samples. For example, Boon et al have mapped lead soap aggregate in crosssections of aged paints, ${ }^{22,23,24}$ and Mazzeo et al applied the same technique to map metal soap formation in reconstructed paint films. ${ }^{12}$ Whilst this methodology allows the chemical differences between layers of paint to be resolved post-degradation, infrared microspectroscopy techniques conventionally suffer diffraction-limited resolution associated with the wavelength of light in the mid-IR spectral range, and are typically restricted to several microns per pixel. ${ }^{25}$ In contrast, the recently developed AFM-IR technique circumvents these limitations by using an AFM probe to detect local photothermal expansion in response to infrared excitation, routinely providing local spectra and infrared mapping with lateral resolution $<50 \mathrm{~nm} .{ }^{26}$ AFM-IR has previously been applied to map chemical heterogeneity and water transport 
within an unpigmented epoxy-phenolic lacquer. ${ }^{27,28,29}$ In this study, we extend this approach to a model linseed oil paint containing titanium dioxide pigments, and apply ATR-FTIR alongside AFM-IR to identify and map the infrared peaks associated with photocatalytic degradation.

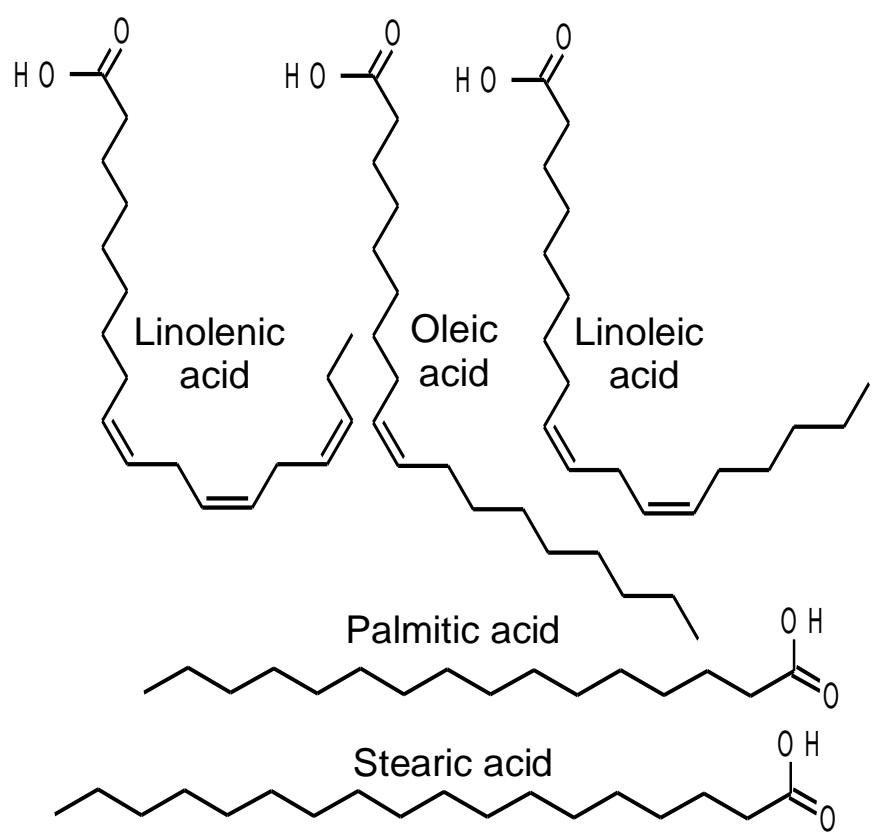

Scheme 1. Chemical structures major fatty acid components of triglyceride molecules in linseed oil.

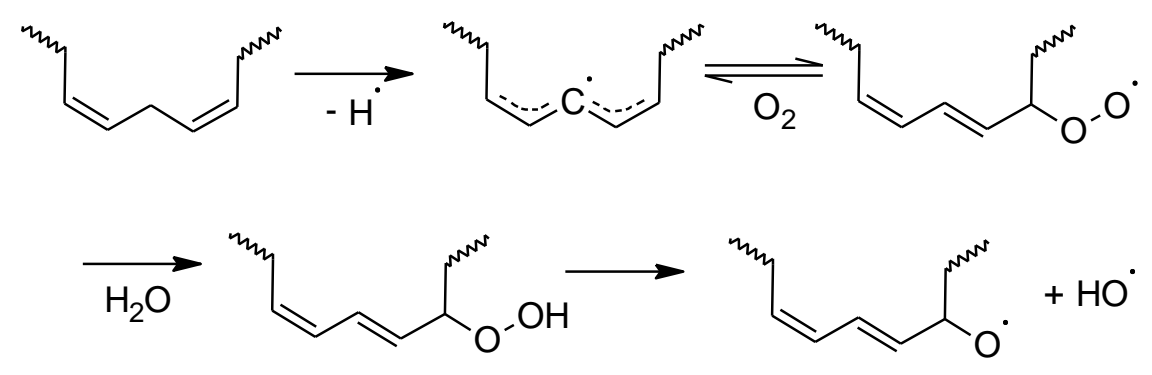

Scheme 2. Proposed mechanism of hydroperoxidation of linoleic acid. 


\section{Experimental}

\section{Sample Preparation}

Model paints with a pigment volume concentration (PVC) of $15 \%$ were prepared by mixing commercially available titanium dioxide (either Hombitan LW uncoated anatase by Sachtleben Chemie or Tronox CR-826, coated rutile by Tronox), bleached commercial linseed oil (van Beek, NL, used without further treatment), and $0.1 \% \mathrm{v} / \mathrm{v}$ drying agent (cobalt and zirconium carboxylates, Pieter Keune, NL). All reagents were used as received. After milling, paint was applied onto Melinex supports using a draw down bar coater, (nominal thickness of $100 \mu \mathrm{m}$ ), and left to dry for 14 days under ambient conditions $\left(T=20^{\circ} \mathrm{C}\right.$, cyclic lighting). Samples were aged in an Opsytec Dr. Gröbel BS-02 UV chamber equipped with UVA lamps (i.e., broad irradiation at wavelengths between $300 \mathrm{~nm}-400 \mathrm{~nm}$ ) and removed periodically. The received UV dose was continuously monitored by a UVA sensor inside the chamber, and then the sample location was corrected for in accordance with the manufacturer's specifications, Table 1. After removal from the UV-chamber, samples were stored under ambient conditions in the dark prior to analysis.

Table 1: UV doses received by coated anatase and uncoated rutile pigmented linseed oil paint samples.

\begin{tabular}{c|cc}
$\begin{array}{c}\text { Irradiation } \\
\text { Step }\end{array}$ & \multicolumn{2}{|c}{ UV Dose $/ \mathbf{~ c m}^{-2}$} \\
\hline Anatase & Rutile \\
\hline $\mathbf{1}$ & 0 & 0 \\
$\mathbf{2}$ & $4.2 \times 10^{3}$ & $3.8 \times 10^{3}$ \\
$\mathbf{3}$ & $5.4 \times 10^{3}$ & $4.7 \times 10^{3}$ \\
$\mathbf{4}^{\star}$ & $6.3 \times 10^{3}$ & $6.3 \times 10^{3}$ \\
$\mathbf{5}^{\star}$ & $7.3 \times 10^{3}$ & $7.2 \times 10^{3}$
\end{tabular}

*local chalking is observed by eye for anatase paint samples

\section{ATR-FTIR}

Bulk infrared spectra were obtained from the paint surface from 16 co-averaged scans collected in ATR mode using an FTIR spectrometer (Perkin Elmer Spectrum $1000 \mathrm{FT}-\mathrm{IR}$ ) operating at $1 \mathrm{~cm}^{-1}$ resolution across the $450-4000 \mathrm{~cm}^{-1}$ range, with a Graseby Specac Golden Gate Single Reflection Diamond ATR. The penetration 
depth of the evanescent wave generated at a diamond internal reflection element is estimated to be $\sim 2 \mu \mathrm{m}$ in the mid-IR range. Spectra were collected from five different locations on each sample.

\section{AFM-IR}

Nanoscale infrared analysis (AFM-IR) was performed on a NanolR2 system (Anasys Instruments) operating with top-down illumination. During AFM-IR analysis, specimens were illuminated by a pulsed, tuneable infrared source (optical parametric oscillator, $10 \mathrm{~ns}$ pulses at a repetition rate of $1 \mathrm{kHz}$, approximate beam spot size 30 $\mu \mathrm{m})$. Sub-diffraction limit resolution is achieved by monitoring the deflection of an AFM probe, which responds to rapid infrared-induced thermal expansions of the sample in contact with the probe tip, Scheme 3. The recorded AFM-IR signal is the amplitude of induced AFM probe oscillation, obtained after fast Fourier transform. This has previously been shown to correlate to infrared absorbance measured using conventional macroscopic FTIR. ${ }^{30}$ Furthermore, since the IR pulse (10 ns duration), thermal expansion, and damping down of the induced oscillation occur on a shorter timescale than the feedback electronics of the AFM, simultaneous contact-mode topographical measurement and infrared mapping can be performed at a given wavelength. ${ }^{31,32,33,34}$ For the present study, AFM-IR images were collected in contact mode at a scan rate of $0.1 \mathrm{~Hz}$ using a gold-coated silicon nitride probe $(0.07-0.4$ $\mathrm{N} / \mathrm{m}$ spring constant, $13 \pm 4 \mathrm{kHz}$ resonant frequency, Anasys Instruments). The amplitude of infrared induced oscillations were recorded at a given wavelength using 16 co-averages for 600 points per 150 scan lines. Spectra were obtained at a single position using 1024 co-averages for each data point. Infrared ratio images were generated using AnalysisStudio software (v3.8, Anasys Instruments) by division of the overlapping regions of IR amplitude maps, cross-correlated using the corresponding height images. For cross-section analysis, samples were cut using a scalpel and then immediately mounted at $90^{\circ}$ in a sample holder (model SD-103, Bruker) and imaged.

\section{SEM}

Scanning electron microscopy images were obtained using an FEI Quanta 650 field emission gun scanning electron microscope operating in low vacuum mode using an accelerating voltage of $10 \mathrm{kV}$. 


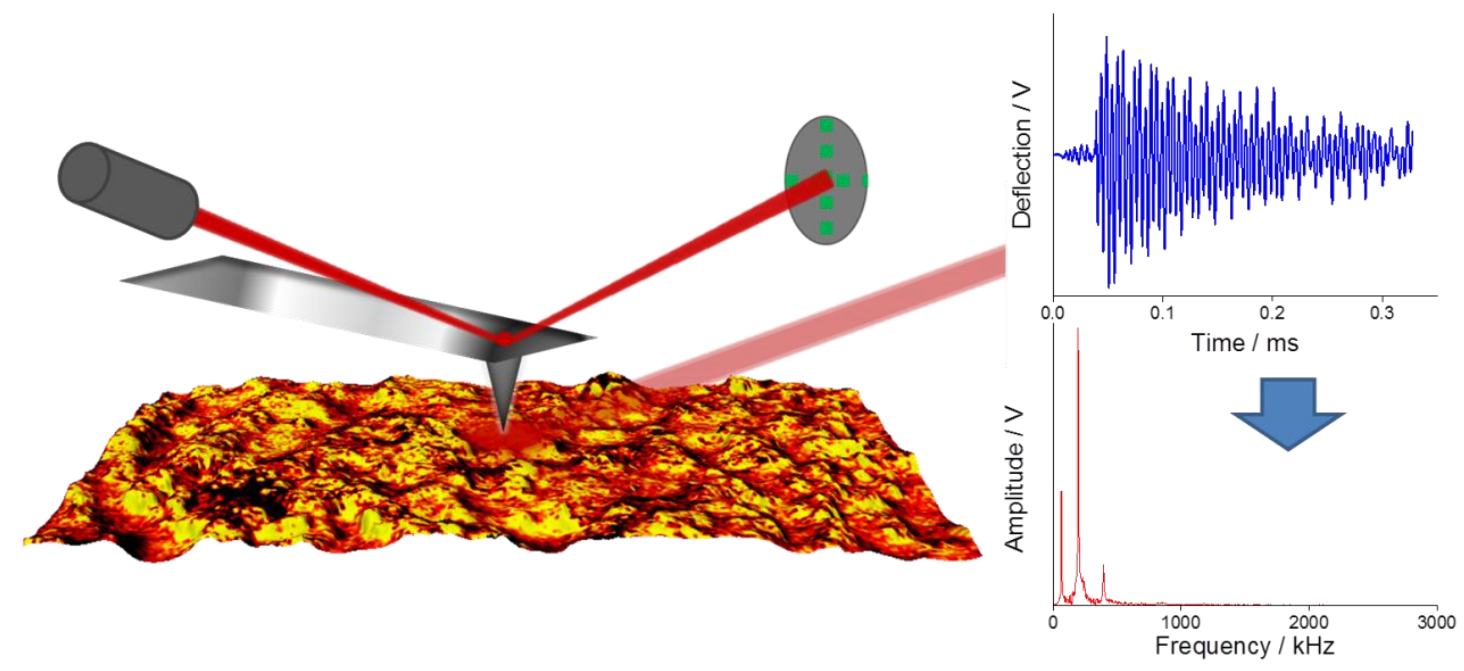

Scheme 3. The AFM-IR experiment with top-down illumination. The IR source is pulsed, inducing rapid thermal expansion of the sample, which is detected by deflection of the AFM probe cantilever. The recorded AFM-IR signal is the amplitude following a fast Fourier transform of the deflection signal. 


\section{Results}

\section{ATR-FTIR}

Before AFM-IR analysis, specimens were investigated using bulk ATR-FTIR, Figure 1. All samples displayed absorbance peaks characteristic of linseed oil, summarised in Table 2. Prior to UV aging, the absence of a characteristic cis $=\mathrm{C}-\mathrm{H}$ stretch absorbance at $3010 \mathrm{~cm}^{-1}$ indicated that oxidation of the cis unsaturated groups had taken place during drying and storage under ambient conditions. This is in keeping with findings detailed by Lazzari et al, who found that for unpigmented linseed oil, absorption associated with the fatty acid cis alkene groups disappeared within 8 hours drying time. ${ }^{7}$ The dried linseed oil spectra show typically broad carbonyl and hydroxyl absorbance peaks; this is because the alkoxy and peroxy radicals formed by oxidation of the cis unsaturated groups (Scheme 2) react further during drying, generating a variety of functional groups including ethers, esters, acids, alcohols, aldehyde and ketone species. Natural maturing/degradation then occurs as a result of further oxygen sorption and (less favourable) organic radical formation in a continuation of the same process. The resulting complex mixture of functional groups yields characteristically broad overlapping infrared absorbance peaks, where peak assignment is necessarily approximate. Nonetheless, the spectral changes which correspond to aging can readily be identified.

In the case of anatase pigmented samples, UV irradiation produced spectra comparable to those reported for degradation of unpigmented linseed oil (aged thermally, under natural conditions, or by UV acceleration $\left.{ }^{4,7,11,35}\right)$. The intensity of the broad carbonyl peak $\left(\mathrm{C}=\mathrm{O}\right.$ stretch, centred on $\left.1736 \mathrm{~cm}^{-1}\right)$ and hydroxyl region $(\mathrm{OH}$ stretch, $2500-3300 \mathrm{~cm}^{-1}$ ) increased relative to that of characteristic $\mathrm{CH}$ absorbance peaks; at $2930 \mathrm{~cm}^{-1}$ and $2880 \mathrm{~cm}^{-1}(\mathrm{CH}$ stretches $), 1464 \mathrm{~cm}^{-1}\left(\mathrm{CH}_{2}\right.$ scissoring) and $1378 \mathrm{~cm}^{-1}\left(\mathrm{CH}_{2} \mathrm{wag}\right)^{11}$, Figure 1. This has been attributed to the release of volatile short chain alkanes during degradation, in keeping with the literature.,21,36 Furthermore, both the carbonyl and hydroxyl peaks broaden significantly, indicating that an increased range of oxygen functional groups are formed.

In order to assess the effect of UV irradiation in more detail, carbonyl regions were averaged, baseline corrected and normalised relative to the ester peak (at 1736 $\mathrm{cm}^{-1}$ ), Figure 2. It can be seen that upon initial UV exposure, similar features are observed for both the samples containing uncoated anatase pigments (highly photocatalytic) and coated rutile pigments (considered inactive). For example, the broad absorbance around $1640 \mathrm{~cm}^{-1}$, related to the presence of carboxylic acids and 
aldehydes, and at $1717 \mathrm{~cm}^{-1}$, attributed to free acids and ketones, increase in intensity relative to the ester peak. Acid and aldehyde end groups are formed following cleavage around ester groups, ß-scission and oxidation reactions, Scheme 4a. ${ }^{7,35}$ Whilst the broad absorbance centred at $1640 \mathrm{~cm}^{-1}$ is potentially also associated with conjugated $\mathrm{C}=\mathrm{C}$ functionalities (Table 2), we ascribe this absorbance to low molecular weight carboxylic acids and aldehydes, since these are known products of linseed oil oxidation. , $9,36,37,38$ Following the initial UV exposure, the chemical state of the rutile containing samples appears to stabilise, whereas these absorbance peaks continue to grow for anatase-containing samples, confirming that the presence of photocatalytic anatase leads to increased oxidative degradation. In addition, it is notable that the intensity of absorbance at higher wavenumbers (around $1780 \mathrm{~cm}^{-1}$ ) increased upon UV irradiation. This has previously been proposed as a diagnostic peak for linseed oil aging. ${ }^{11}$ Whilst this peak is consistent with the presence of peracids, peresters, lactones or anhydrides, absorbance in this region is widely attributed to lactone formation during the oxidative degradation of estercontaining polymers (e.g., during thermal and UV accelerated aging of acrylic resins, ${ }^{39,40,41,42,43,44}$ via various proposed mechanisms, e.g., Scheme $\left.4 b\right)$. However, in contrast to the progressively increasing absorbance noted at lower wavenumbers, the intensity of this peak stabilised after the initial UV dose for both the rutile and anatase samples.

(a)

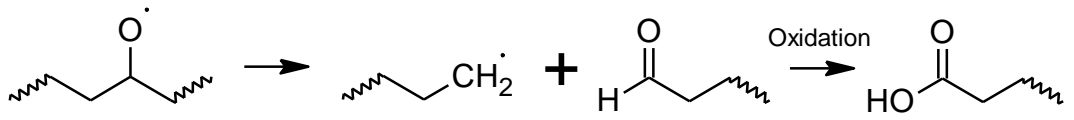
$\mathrm{O} 2, \mathrm{RH} \downarrow$

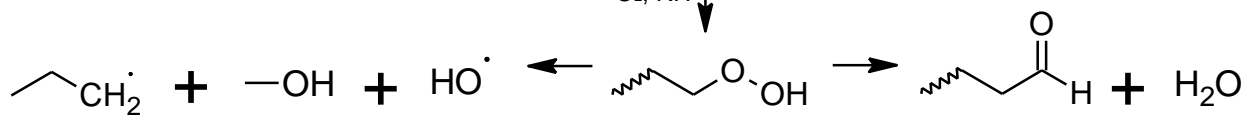

(b)<smiles>CCCCCCC(C)(C)C(=O)OC(C)(C)C</smiles>

Scheme 4. Suggested mechanistic pathways for the degradation of linseed oil paint: (a) the formation of aldehydes and carboxylic acids by B-scission and oxidation; and (b) the formation of $y$-lactones. 


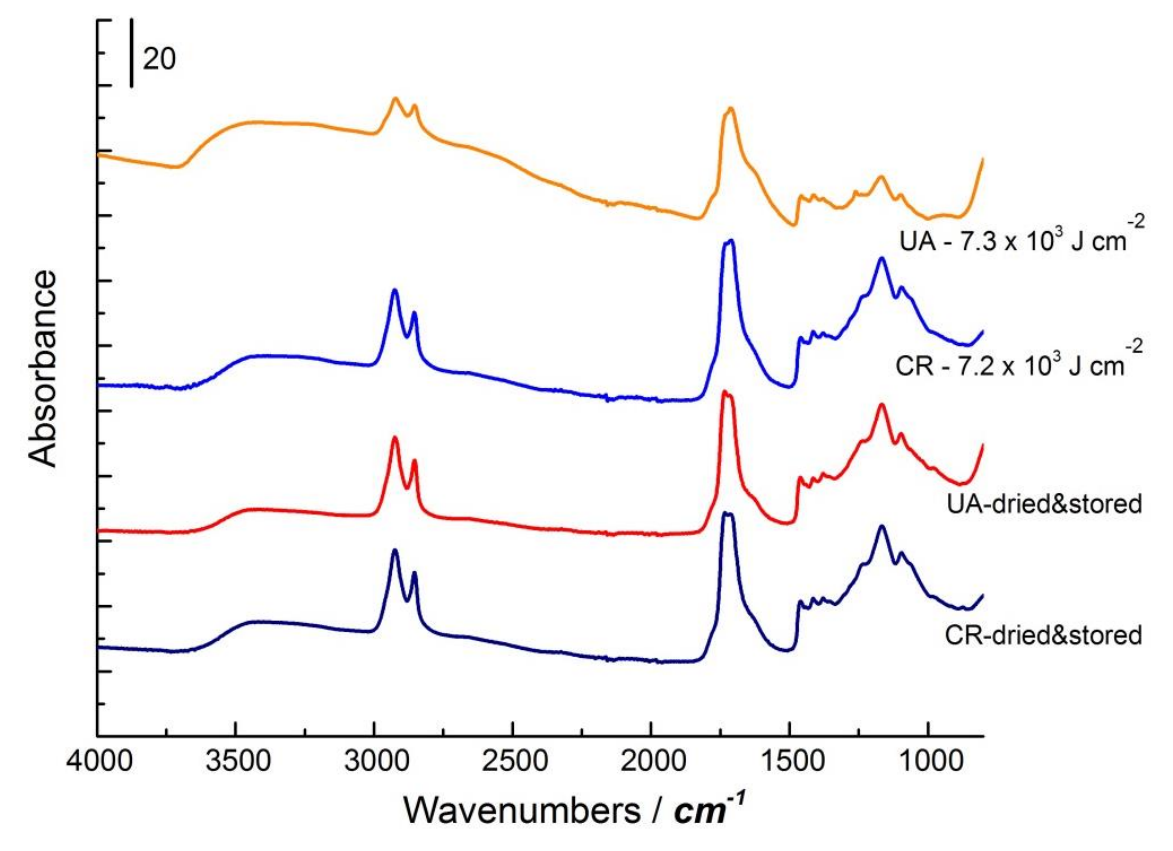

Figure 1: ATR mode FTIR spectra of linseed oil samples pigmented with uncoated anatase (UA) or coated rutile (CR) after drying under ambient conditions for 14 days and storage, and after drying under ambient conditions for 14 days followed by exposure to $7.3 \times 10^{3} \mathrm{~J} \mathrm{~cm}^{-2} \mathrm{UV}$ or $7.2 \times 10^{3} \mathrm{~J} \mathrm{~cm}^{-2} \mathrm{UV}$ respectively, followed by storage.
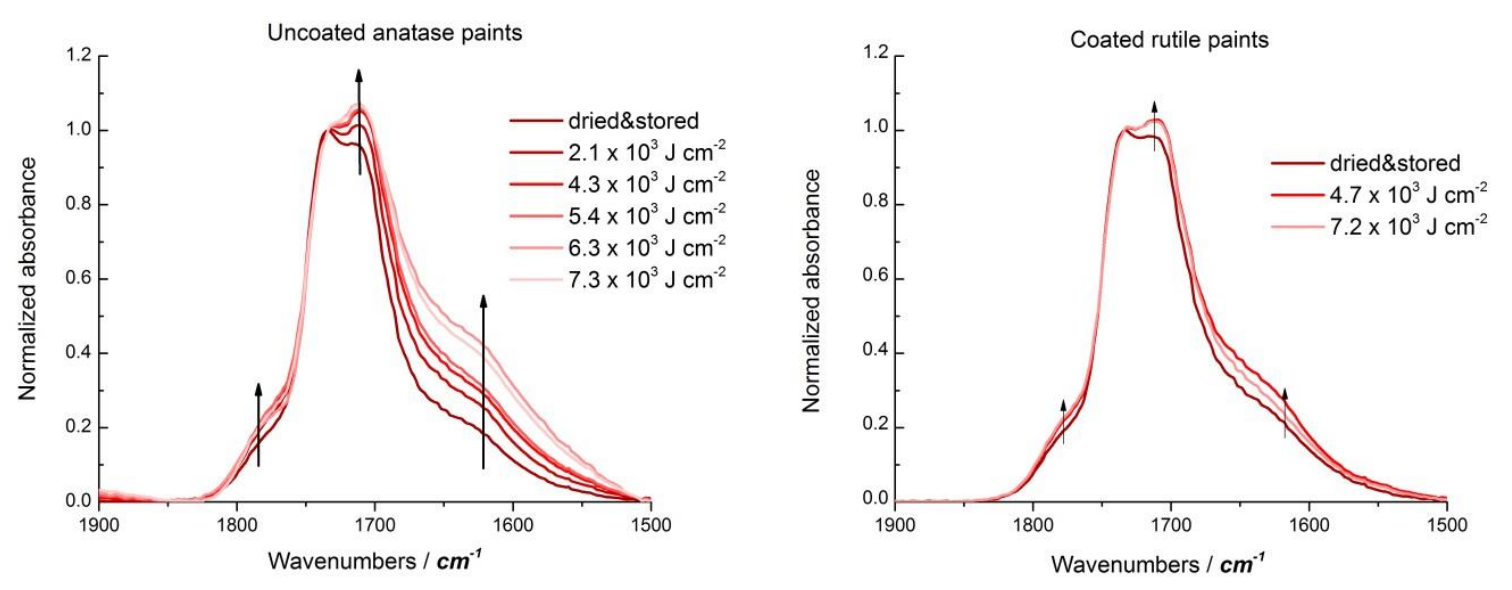

Figure 2. Baseline corrected infrared spectra for linseed oil samples pigmented with $15 \%$ PVC anatase or rutile forms of $\mathrm{TiO}_{2}$ before and after increasing levels of exposure to UV. Spectra are normalised to the $1736 \mathrm{~cm}^{-1}$ ester peak, and each spectrum is the mean of 5 individual spectra gathered from various positions of the specimen. 
Table 2: Linseed oil infrared peak assignments.

\begin{tabular}{|c|c|}
\hline Wavenumber & Peak assignment \\
\hline$\sim 3393 \mathrm{~cm}^{-1}$ & hydroperoxide, alcohol and acid $\mathbf{O}-\boldsymbol{H}$ stretch \\
\hline $2919 \mathrm{~cm}^{-1}$ & alkyl $\mathrm{CH}-\mathrm{CH}_{2} \mathrm{C}-\mathrm{H}$ stretch \\
\hline $2852 \mathrm{~cm}^{-1}$ & alkyl $\mathrm{CH}-\mathrm{CH}_{2}$ and $\mathrm{CH}_{3} \mathbf{C}-\boldsymbol{H}$ stretch \\
\hline$\sim 2650 \mathrm{~cm}^{-1}$ & $\mathbf{O}-\mathbf{H}$ from $(-\mathrm{OH}) \mathrm{COOH}$, broadening of $\mathbf{O}-\mathbf{H}$ due to carboxylic acids. \\
\hline $1780 \mathrm{~cm}^{-1}$ & peracids, peresters, $\gamma$-lactones and anhydrides $\mathbf{C}=\mathbf{O}$ stretch. \\
\hline $1736 \mathrm{~cm}^{-1}$ & ester $\boldsymbol{C}=\mathbf{O}$ stretch \\
\hline $1717 \mathrm{~cm}^{-1}$ & saturated ketones and free fatty acid $\mathbf{C}=\mathbf{O}$ stretch. \\
\hline$\sim 1640 \mathrm{~cm}^{-1}$ & Conjugated $\mathbf{C}=\boldsymbol{C}$ stretch, acid or aldehyde $\mathbf{C}=\mathbf{O}$ stretch \\
\hline$\sim 1613 \mathrm{~cm}^{-1}$ & Aldehyde, carboxylic acids and $\alpha / \beta$ unsaturated ketone $C=O$ stretch. \\
\hline $1463 \mathrm{~cm}^{-1}$ & Alkyl $\mathrm{CH}-\mathrm{CH}_{2}, \mathrm{CH}_{3} \mathbf{C}-\boldsymbol{H}$ bending \\
\hline $1410 \mathrm{~cm}^{-1}$ & Acid $\mathbf{C}-\mathbf{O}$ bend, $-\mathrm{CH}_{2}-\mathrm{CO}-\mathrm{O} \mathbf{C}-\boldsymbol{H}$ bending \\
\hline $1377 \mathrm{~cm}^{-1}$ & Alkyl $\mathrm{CH}_{2} \mathrm{C}-\boldsymbol{H}$ bending \\
\hline $1054 \mathrm{~cm}^{-1}$ & Alcohol C-O stretch. \\
\hline
\end{tabular}

\section{AFM-IR}

Localised infrared spectra were initially obtained for the anatase paints before and after extensive UV irradiation (step 5). This was achieved by positioning the AFM-IR probe in contact with the sample surface, and stepping pulsed radiation incident on the probe tip through the mid-IR fingerprint range $\left(900 \mathrm{~cm}^{-1}-1900 \mathrm{~cm}^{-1}\right)$. The amplitude of probe oscillations induced by thermal expansion of the sample (IR amplitude) was then monitored and plotted to produce spectra, where peak positions were found to be in broad agreement with those produced using bulk ATR FTIR, Figure 3. 

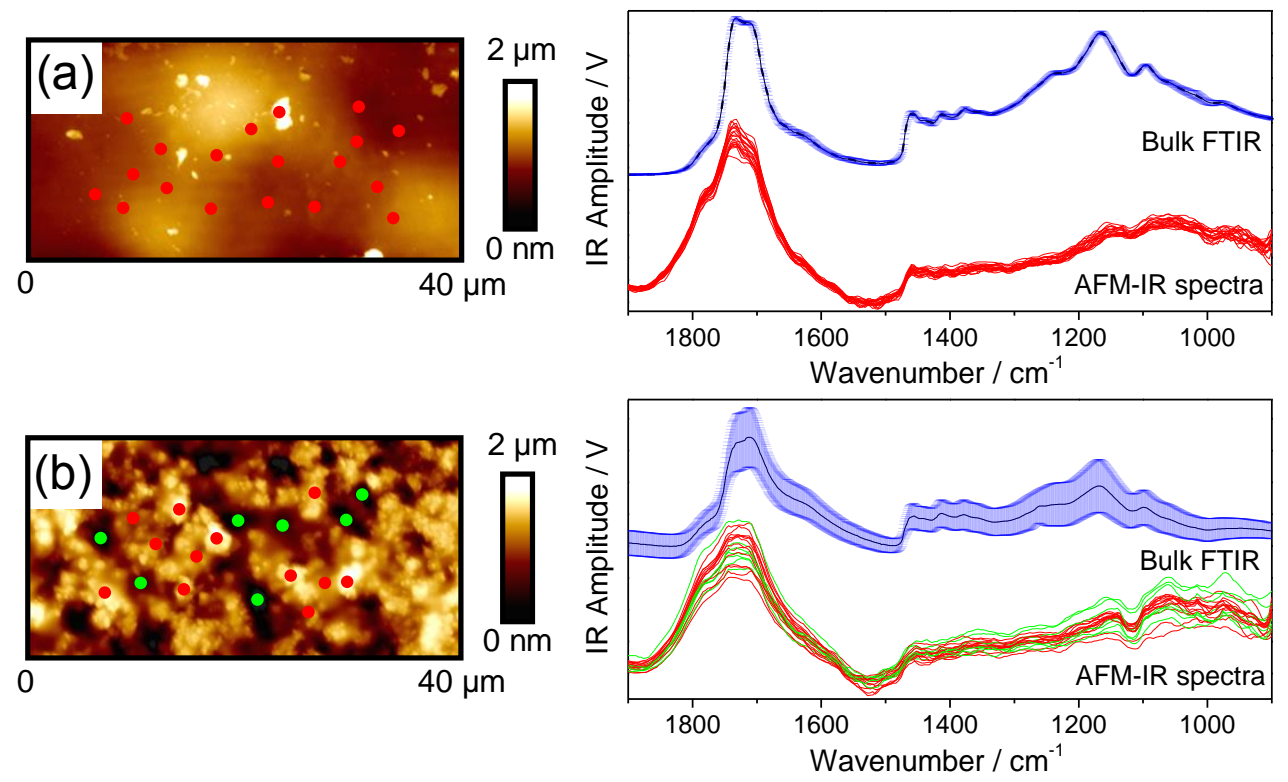

Figure 3. AFM-IR contact mode height images (left) alongside ATR-FTIR spectra and AFM-IR spectra (right) corresponding to tip locations indicated by markers for samples of linseed oil pigmented with uncoated anatase after (a) drying under ambient conditions for 14 days and dark storage; (b) drying under ambient conditions for 14 days followed by exposure to $7.3 \mathrm{x}$ $10^{3} \mathrm{~J} \mathrm{~cm}^{-2} \mathrm{UV}$ and dark storage (irradiation step 5). ATR-IR spectra correspond to the mean of 5 individual measurements, and error bars correspond to 1 standard deviation.

Contact mode AFM height profiles revealed increasing surface roughness of the paints pigmented with anatase during UV irradiation, in keeping with previously reported tapping mode AFM images and gloss measurements, ${ }^{16}$ Figure 3 . XPS analysis has previously shown that titanium is detected in concert with this roughening, indicating that pigments become gradually exposed. ${ }^{16}$ To verify this, SEM analysis and EDX mapping was performed, which demonstrated that raised areas indeed correspond to locally increased concentrations of titanium at the surface, Figure 4.

For the rougher, aged specimens, local AFM-IR spectral intensity was found to vary more across the sample, Figure 3. A similar effect was observed for bulk infrared spectra, where variations were found to increase dramatically after UV doses of $5.4 \times 10^{3} \mathrm{~J} \mathrm{~cm}^{-2}$ or more. The intensity of local AFM-IR spectra did not however specifically correlate to 'high' or 'low' areas of the surface profile, Figure 3b. The relative signal intensity is instead proposed to change as a result of both chemical heterogeneity and local variations in the effective sampling volume caused by the presence of underlying pigment particles. This is because during AFM-IR, the sampling volume is not limited by the penetration of infrared radiation, but by the volume of material under the AFM-IR probe tip that contributes to the thermal 
expansion 'felt' by the probe. Both the thermal expansion co-efficient and infrared absorbance of titianium dioxide are negligible in comparison to the organic binder, so the effective sampling depth is considered to be limited to material between the probe and nearest underlying pigment.
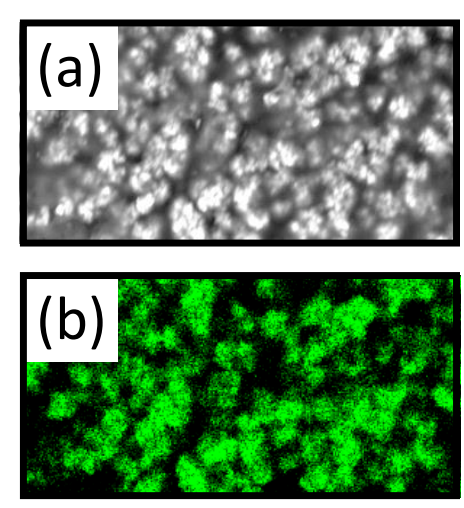

Figure 4. $20 \mu \mathrm{m} \times 10 \mu \mathrm{m}$ scanning electron microscopy images of the model anatase pigmented linseed oil paint surface following drying under ambient conditions for 14 days and exposure to $7.3 \times 10^{3} \mathrm{~J} \mathrm{~cm}^{-2}$ UV (irradiation step 5): (a) secondary electron image and (b) energy dispersive $\mathrm{x}$-ray spectroscopy map for titanium.

In light of this, direct comparison of the UV irradiated anatase samples was achieved using averaged AFM-IR spectra normalized to the ester $\mathrm{C}=\mathrm{O}$ absorbance at $1736 \mathrm{~cm}^{-1}$, similar to the bulk FTIR analysis presented in Figure 2. Inspection of the carbonyl region after UV exposure revealed a relative increase in absorbance associated with degradation products, namely carboxylic acids and aldehydes at $1640 \mathrm{~cm}^{-1}$, free acids and ketones at $1710 \mathrm{~cm}^{-1}$ and lactones at $1780 \mathrm{~cm}^{-1}$, Figure $5 .{ }^{45}$ Note that whilst these spectral changes appear minor, this analysis was repeated in three different regions for each sample, and the relative changes in absorbance were found to be consistent within each data set. It was, however, noted that the absorption at $1780 \mathrm{~cm}^{-1}$ appears far more pronounced in the AFM-IR spectra than in ATR-FTIR, whereas the increases in absorbance at lower wavenumbers (1710 and $1640 \mathrm{~cm}^{-1}$ ) are less prominent. This can be potentially be explained by the difference in detection techniques (i.e., a difference in the thermal expansion coefficients for various chemical species) or a concentration gradient at the paint surface, since AFM-IR is expected to be more surface sensitive. In reality, both effects appear to contribute; the presence of a concentration gradient through samples was verified by AFM-IR analysis on the reverse of paint specimens, removed from the Melinex support using a scalpel, Figure 6. 

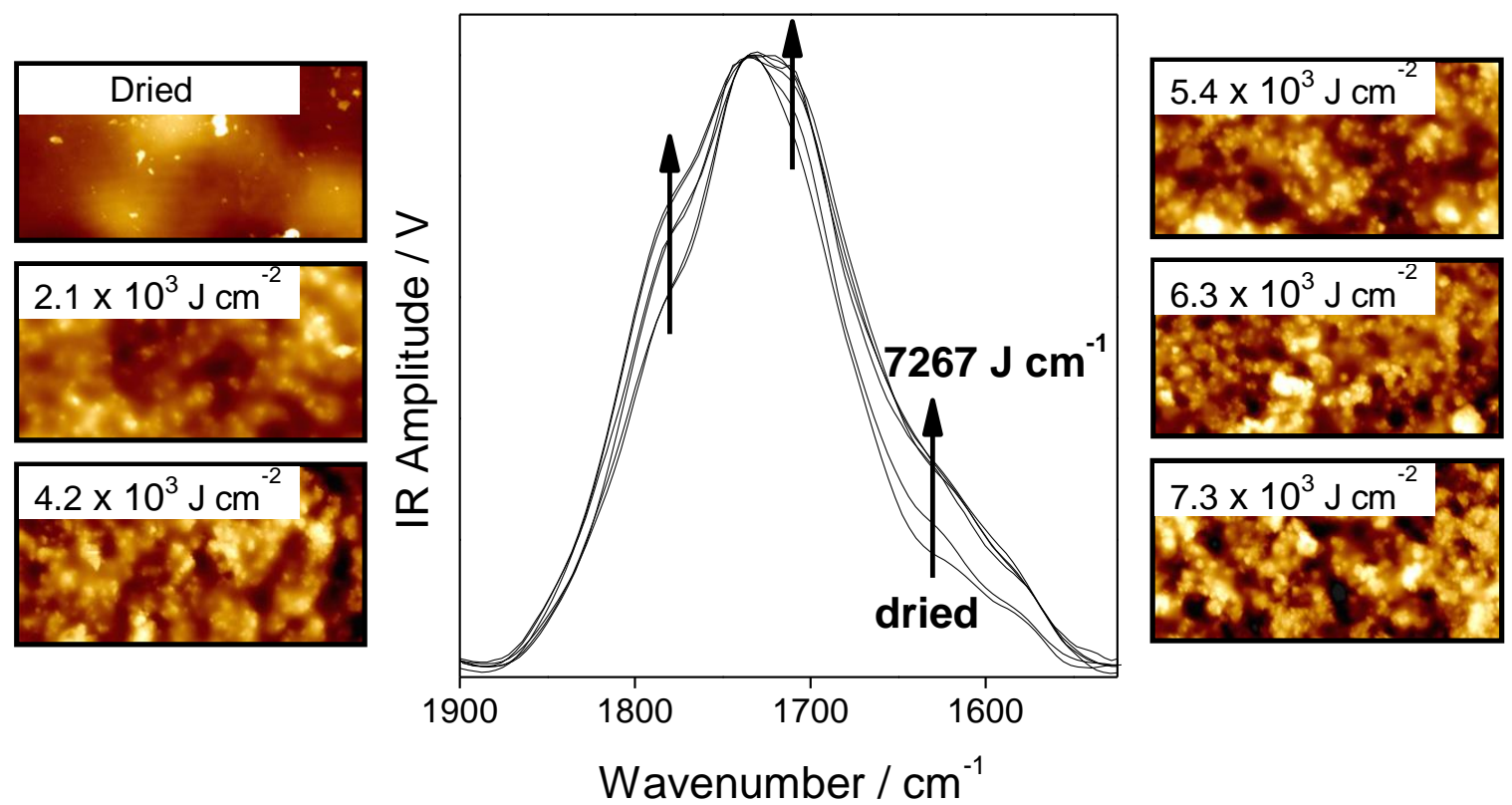

Figure 5. $40 \mu \mathrm{m} \times 20 \mu \mathrm{m}$ contact mode AFM images of linseed oil samples pigmented with uncoated anatase after drying under ambient conditions for 14 days, and after exposure to increasing UV doses (irradiation steps 1 to 5), alongside the carbonyl region of AFM-IR spectra produced by averaging 20 AFM-IR spectra gathered from random positions within each of these regions. For comparison, spectra are normalised to the $1736 \mathrm{~cm}^{-1}$ ester band. $Z$ scale for AFM images is $2 \mu \mathrm{m}$.

Due to the imprecise detachment method, direct comparison between the spectra gathered from reverse side of different samples is not possible (the apparent roughness of the reverse of aged rutile pigmented samples is a sampling artefact). Nonetheless, carbonyl peaks detected at the back of detached paint films were consistently found to be more defined than those gathered from the front, i.e., the shoulder peaks associated with degradation were comparatively attenuated, Figure 6. Interestingly, this was also found to be the case for anatase pigmented samples examined before UV aging, and control samples prepared using the less active coated rutile form of titanium white. This can be explained by consideration of the linseed oil curing and aging mechanisms, since whilst the precise penetration depth of UV, moisture and oxygen are not known, the outer surface of the paints is more exposed. Indeed, Zumbühl et al. recently demonstrated gradients of oxidation in oil paint cross sections using ATR-FTIR spectroscopy, ${ }^{37}$ finding high concentrations of polar chemical groups toward paint surfaces, and this is in line with the reported preferential formation of azeleic acids at the surface ${ }^{9}$. In the present case, natural aging and photocatalytic aging can be seen to induce similar spectral changes but at a significantly different rate, which is in keeping with the titanium white acting as a radical initiator (a direct comparison between spectra gathered from the surface of 
UV aged anatase and rutile spectra is given in Figure 7). In the case of rutile control samples however, the UV-induced process is sufficiently retarded that spectra obtained from the front of samples change little as a consequence of UV irradiation, and no increases in roughness are observed.
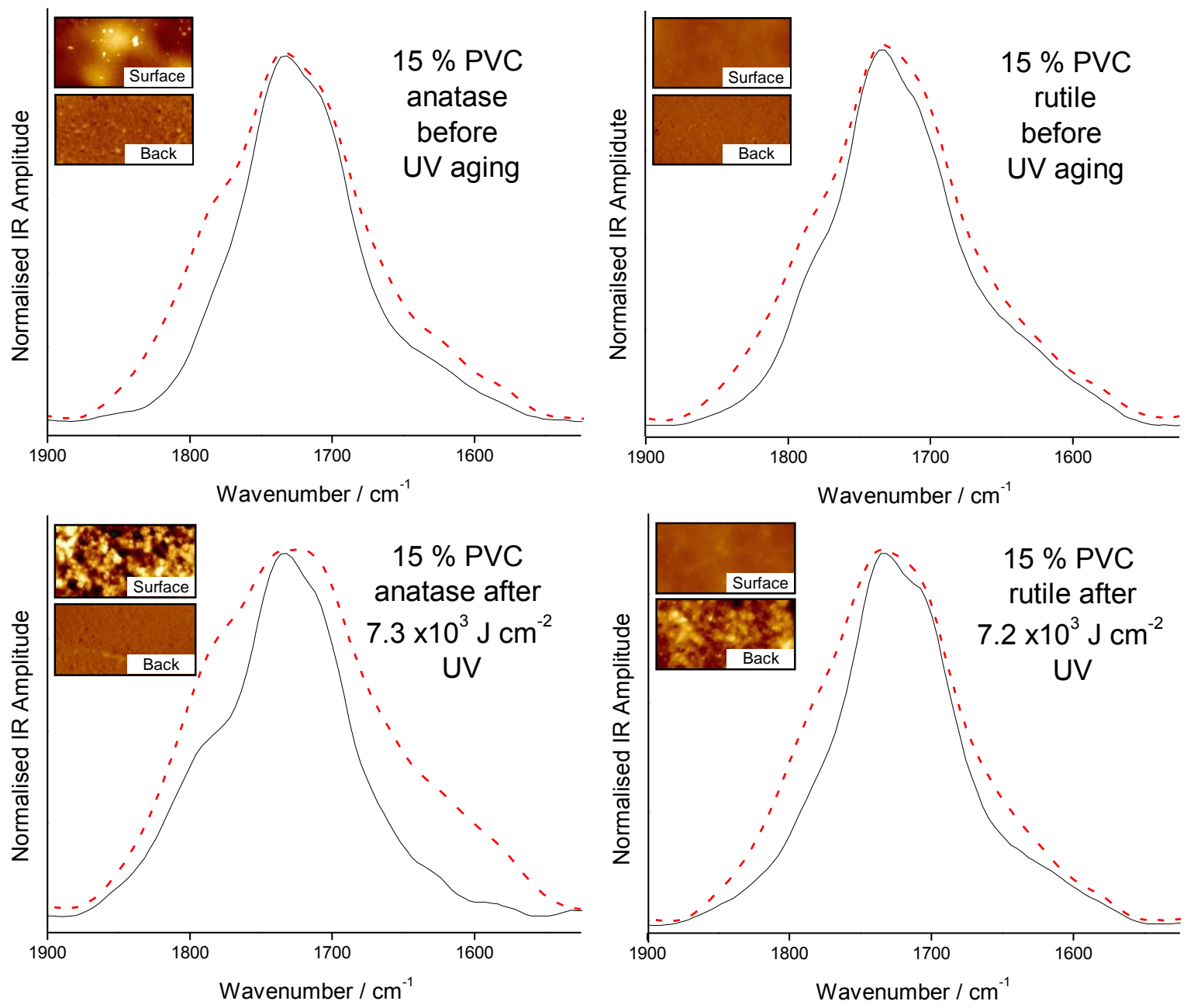

Figure 6. AFM-IR contact mode height images ( $z$ scale is $2 \mu \mathrm{m}$ ) and the carbonyl region of spectra produced by averaging 20 AFM-IR spectra taken from random positions within the imaged region. Spectra were gathered from the front (red dashed line) and reverse (black solid line) side of linseed oil samples pigmented with the uncoated anatase and coated rutile forms of titanium dioxide before and after extensive UV aging (irradiation step 5). 


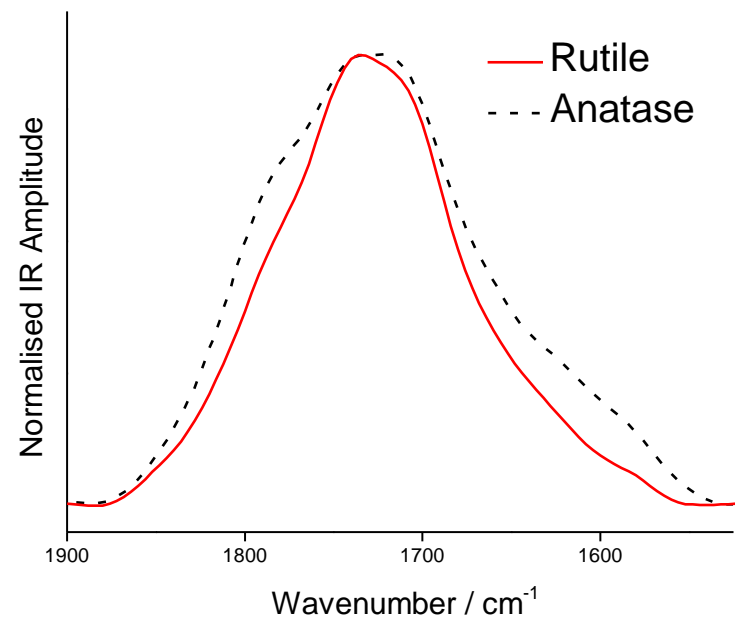

Figure 7. Comparison of the carbonyl region of spectra produced by averaging 20 AFM-IR spectra taken from the surface of linseed oil samples pigmented with the uncoated anatase (black dashed line) and coated rutile (red line) forms of titanium dioxide after drying under ambient conditions for 14 days and exposure to $7.3 \times 10^{3} \mathrm{~J} \mathrm{~cm}^{-2}$ and $7.2 \times 10^{3}$ doses of UV respectively (irradiation step 5).

The generation of degradation products at the surface of the anatasepigmented paints was further investigated by AFM-IR mapping, Figure 8. Infrared amplitude maps were gathered at $1640 \mathrm{~cm}^{-1}$ (corresponding to carboxylic acid and aldehyde groups produced during aging), $1736 \mathrm{~cm}^{-1}$ (corresponding to ester groups) and $1780 \mathrm{~cm}^{-1}$ (corresponding to lactone groups produced during aging), and these varied in line with height images. This confirms that the local amplitude signal corresponds to the effective sampling volume between the probe tip and underlying pigment particles. ${ }^{46}$ In order to overcome this and isolate chemical differences, ratio images were generated by division of the infrared amplitude data gathered at different wavenumbers, Figure 8. In the case of dried and stored samples which had not been exposed to UV aging, ratio images generated from $1640 \mathrm{~cm}^{-1} / 1736 \mathrm{~cm}^{-1}$ (showing the location of carboxylic acid and aldehyde degradation products in relation to esters) and $1780 \mathrm{~cm}^{-1} / 1736 \mathrm{~cm}^{-1}$ (corresponding to the location of lactones in relation to esters) were relatively homogeneous, confirming that differences in the amplitude signal due to sampling volume effectively cancel out. In contrast, immediately after exposure to UV $\left(2.1 \times 10^{3} \mathrm{~J} \mathrm{~cm}^{-2}\right.$ dose $)$, ratio images revealed a heterogeneous distribution of degradation products around raised areas (e.g., circled regions, central column of Figure 8) which are attributed to anatase pigment clusters. Further UV exposure yielded more homogeneous ratio images, (obtained under identical imaging conditions), indicating increased coverage of the surface with degradation products. 


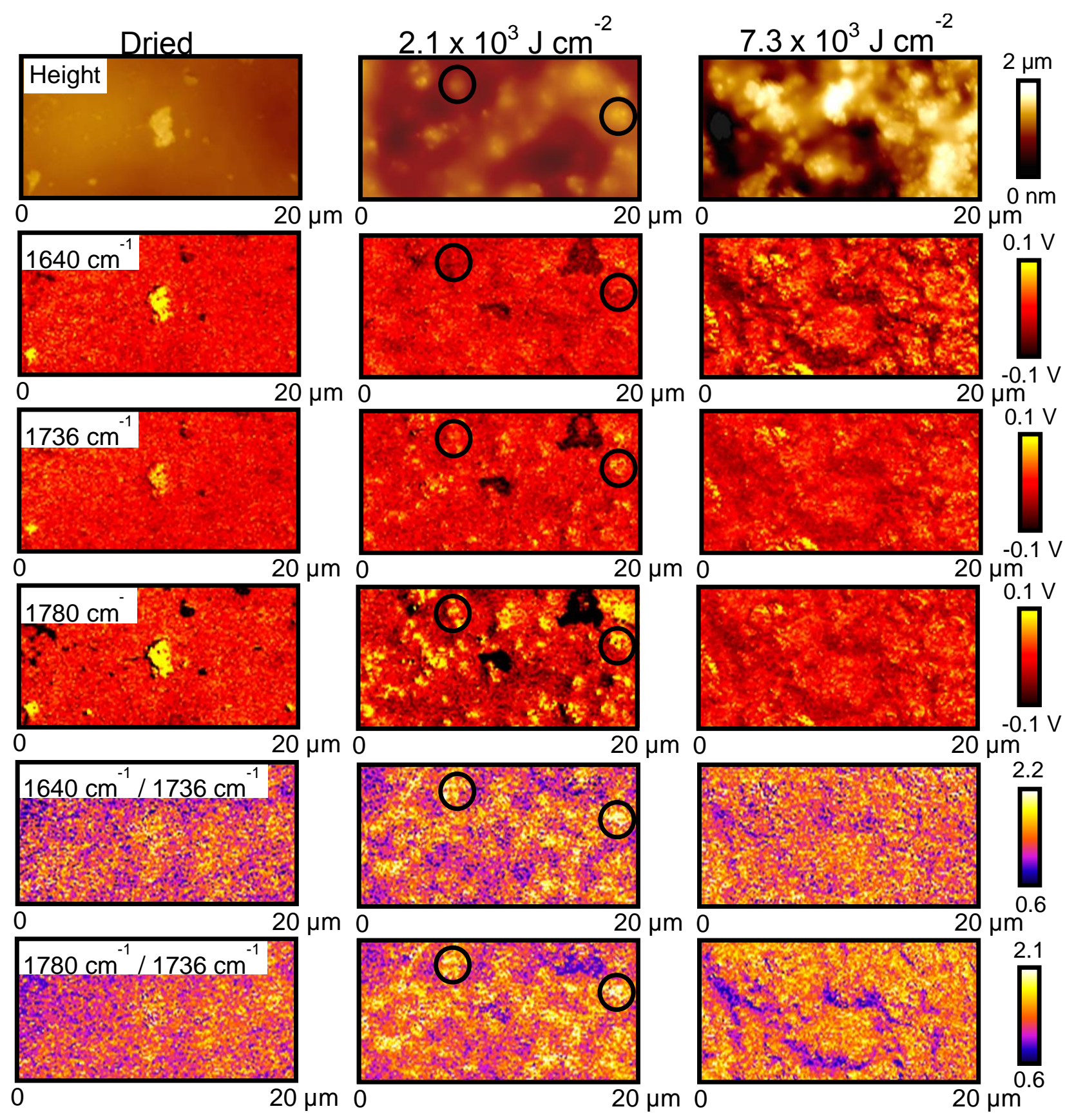

Figure 8. $20 \mu \mathrm{m} \times 10 \mu \mathrm{m}$ AFM-IR height images and corresponding infrared maps of linseed oil paint pigmented with anatase after drying under ambient conditions for 14 days, after exposure to $2.1 \times 10^{3} \mathrm{~J} \mathrm{~cm}^{-2} \mathrm{UV}$ (irradiation step 1), and after exposure $7.3 \times 10^{3} \mathrm{~J} \mathrm{~cm}^{-2} \mathrm{UV}$ (irradiation step 5). To identify local variations in signal, IR amplitude images gathered at $1640 \mathrm{~cm}^{-1}, 1736 \mathrm{~cm}^{-1}$ and $1780 \mathrm{~cm}^{-1}$ are flattened by centring each scan line around zero. Ratio images generated from raw data are also presented for $1640 \mathrm{~cm}^{-1} / 1736 \mathrm{~cm}^{-1}$ (showing the location of carboxylic acid functional groups) and $1780 \mathrm{~cm}^{-1} / 1736 \mathrm{~cm}^{-1}$ (corresponding to the location of lactone functional groups). 


\section{Discussion}

Numerous investigators have previously reported FTIR analysis of linseed oil paint degradation, describing the appearance of characteristic absorbance peaks which may be of use in a diagnostic device ${ }^{7,11,21}$. In the present case, infrared spectra revealed that the breakdown of linseed oil containing anatase pigments generally involves increased absorbance at wavenumbers consistent with lactone and carboxylic acid and aldehyde species, alongside the release of short chain volatiles, in keeping with previous reports. However, the concentration of lactones stabilised rapidly, and its role in degradation is unclear. In the case of carboxylic acids, it has been documented that hydrolytic attack may lead to the preferential formation of short chain di-carboxylic acids near the surface of oil paint samples..$^{8,9,37,38}$ The origin of detected carboxylic acid species within a given sample (i.e., hydrolysis or photocatalytic radical attack), cannot be gauged directly using infrared techniques, precluding the use of this absorbance as a direct measure of catalytic activity. Nonetheless, comparison of AFM-IR and ATR-IR analysis of rutile and anatase pigmented paint performed here gives some insights into the degradation mechanism, pointing towards a predominately photocatalytic radical-induced mechanism for the formation of carboxylic acids and aldehydes in the presence of anatase pigments.

Oxidation and hydrolysis during drying is supported by the fact that the surface of both anatase and rutile pigmented samples were found to differ substantially from the bulk prior to UV aging. The formation of carboxylic acids and aldehydes concentrated towards the surface is expected, since the outer surface of the paint sample is directly exposed to ambient oxygen, humidity and light. Whilst ATR-FTIR spectra indicate that this process continues on initial illumination with UV, in the case of rutile pigmented samples the chemical state then stabilised. This may be because the relatively inactive rutile pigments provide a protective effect by absorbing UV without producing further radicals, preventing degradation deeper in the film (i.e., UV-initiated oxidation is limited to the exposed surface, and the reactions producing lactone, aldehyde and acid species are therefore slowed in comparison to the anatase samples). In contrast, chemical change continued for anatase paints, and this is characteristic of a photocatalytic process, where UV illumination of the semi-conductor pigment provides reactive electrons at the surface of particles to initiate further degradation.

In the case of lactones, ATR-FTIR analysis indicated that their formation occurs immediately upon UV illumination, but then rapidly stabilised, even as 
degradation visibly continued. This indicates that lactones are a transient species formed during linseed oil degradation. Indeed, AFM-IR analysis confirmed that lactones are concentrated towards the sample surface, where the greatest degree of oxidation is expected to occur. In contrast, the measured absorbance of other degradation products (acids, aldehydes and ketones) was found to stabilise when measured using AFM-IR, whilst continuing to increase in the less surface sensitive bulk FTIR spectra. Given that AFM-IR mapping also showed a relatively homogeneous concentration of degradation products is ultimately established across the paint surface, we propose that within the sampling depth of AFM-IR, a dynamic surface layer is formed where the generation of degradation products is matched by their further breakdown and release as volatile species. It is suggested that lactones are predominately produced within this region, leading to increasing absorbance in the AFM-IR spectra until full surface coverage is achieved. Upon further UV exposure, acids, aldehydes and ketones are generated deeper inside the paint and their increasing absorbance can be detected using ATR-FTIR (but not AFM-IR). Support for this proposed mechanism was found by cross-sectional AFM-IR analysis of an anatase pigmented sample cut after UV aging (irradiation step 5). Lactone absorbance was found to be concentrated towards the paint film surface, whereas absorbance associated with acids and aldehydes was found be more intense deeper inside the coating, Figure 9. Note, however, that this cross-section was prepared using a scalpel under ambient conditions and this places limitations on any further interpretation of the data (due to an imprecise cutting angle, potential smearing of degradation products etc.).

A previously suggested disadvantage of infrared spectroscopy in conservation science is that significant changes in the detected peak positions and intensities coincide with visible paint degradation. ${ }^{16}$ In the present case, visible degradation was only evident in the case of anatase samples exposed to UV doses of $6.3 \times 10^{3} \mathrm{~J} \mathrm{~cm}^{-2}$ or more, whereas normalised FTIR spectra showed significant changes for the degrading paint well in advance of this exposure, Figure 3 . From the discussion above it is however evident that infrared absorbance at a given wavelength cannot be used to directly ascertain the level of degradation. Instead, a better approach would be to monitor the carboxylic acid/aldehyde absorbance relative to that of esters. Despite the overlapping, broad nature of these peaks, the relative changes described were consistently detected for degraded paint specimens using both infrared spectroscopy techniques. Nonetheless, this alone cannot provide a direct measure of the level of degradation, since both species are formed during drying and aging, and furthermore, initial concentrations will depend on the source of 
linseed oil. Monitoring the changes in this ratio over time will, however, give an indication of the degradation kinetics. This opens up the tantalising possibility that the emerging field of handheld infrared technologies could provide a convenient nondestructive diagnostic device in the field of cultural heritage. ${ }^{47}$ This would require a systematic and long term approach for preventive condition monitoring within art collections, taking spectra at fixed locations on a painting at specific time intervals ( 3 , 5,10 years) and is of potential interest not only for photocatalytic degradation in the presence of titanium white, but also to monitor natural aging and other degradation phenomena such as soap formation below the surface.
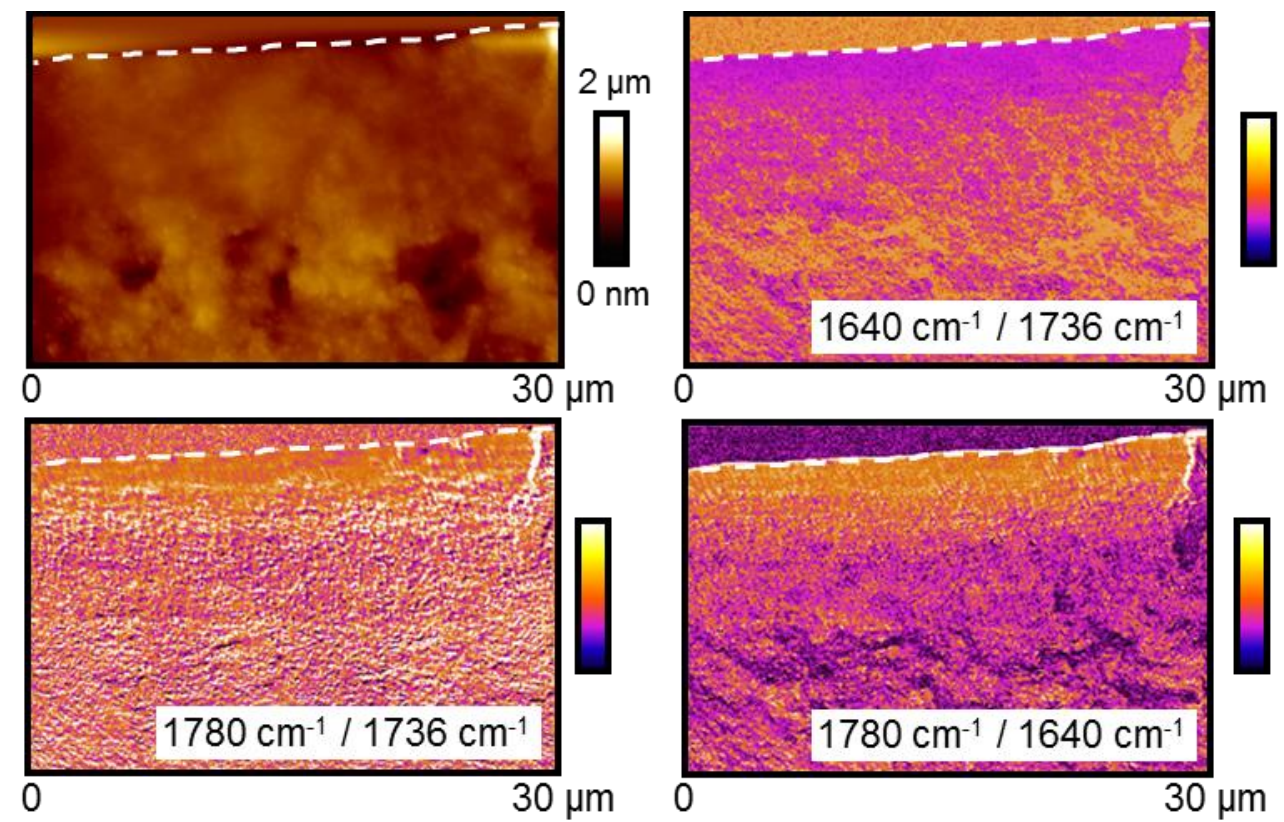

Figure 9. $30 \mu \mathrm{m} \times 20 \mu \mathrm{m}$ AFM-IR height and ratio images corresponding to an uncoated anatase pigmented linseed oil paint cross-section exposed to a $7.3 \times 10^{3} \mathrm{~J} \mathrm{~cm}^{-2}$ dose of UV (irradiation step 5), held at $90^{\circ}$ immediately after cutting through with a scalpel (no embedding). White dashed lines correspond to the outer surface of the paint, ratio images correlate to the location of carboxylic acids and aldehydes relative to esters $\left(1640 \mathrm{~cm}^{-1} / 1736\right.$ $\left.\mathrm{cm}^{-1}\right)$; lactones relative to esters $\left(1780 \mathrm{~cm}^{-1} / 1736 \mathrm{~cm}^{-1}\right)$ and lactones relative to carboxylic acids and aldehydes $\left(1780 \mathrm{~cm}^{-1} / 1640 \mathrm{~cm}^{-1}\right)$.

Finally, it is noteworthy that the results presented in this paper represent the first application of sub-diffraction limit infrared mapping to pigmented coatings, demonstrating the potential of the recently developed AFM-IR technique in this field. This approach could be used to generate further insights in cultural heritage research, where envisioned examples include the spatially resolved characterization of local drying and aging effects, the study of metal soap formation, detailed pigmentbinder interactions ${ }^{12,23}$, and cleaning studies on reconstructed paint samples (e.g., mapping the residues of the cleaning agent on the paint surface). ${ }^{10,48}$ 


\section{Conclusions}

Sub-diffraction limit AFM-IR imaging has provided direct evidence for locally induced photocatalytic degradation in the vicinity of anatase titanium white pigments at the surface of linseed oil paints. A spectral signature associated with the products of radical oxygenation reactions has been identified, and this can also be detected using bulk FTIR methods prior to visible degradation. Moreover, the combination of these varyingly surface sensitive techniques has been used to differentiate between the relative concentrations of degradation products through the depth of paint films.

\section{Acknowledgments}

The authors are grateful to AkzoNobel for financial support, materials, and S. Gibbon and B. Rossenaar specifically for their expertise. Suzan de Groot is acknowledged for training on the ATR-FTIR. The authors also thank J. Hermans and K. Keune for fruitful discussions and help with interpretation. Finally P.Kooyman is acknowledged for her involvement in Van Driel's PhD research. 


\section{References}

(1) Rasti, F.; Scott, G. The Effects of Some Common Pigments on the PhotoOxidation of Linseed Oil-Based Paint Media. Stud. Conserv. 1980, 25, 145156.

(2) Privett, O. S.; Blank, M. L.; Lundberg, W. O. An Accelerated Test of the Yellowing Tendency of Drying Oils. J. Am. Oil Chem. Soc. 1961, 38, 27-30.

(3) Mills, J. S. The Gas Chromatographic Examination of Paint Media. Part I . Fatty Acid Composition and Identification of Dried Oil Films. Stud. Conserv. 1966, 11, 92-107.

(4) Mallégol, J.; Gardette, J. L.; Lemaire, J. Long-Term Behaviour of Oil-Based Varnishes and Paints I. Spectroscopic Analysis of Curing Drying Oils. J. Am. Oil Chem. Soc. 1999, 76, 967-976.

(5) Mallégol, J.; Gardette, J. L.; Lemaire, J. Long-Term Behaviour of Oil-Based Varnishes and Paints II. Fate of Hydroperoxides in Drying Oils. J. Am. Oil Chem. Soc. 2000, 77, 249-255.

(6) Mallégol, J.; Gardette, J. L.; Lemaire, J. Long-Term Behaviour of Oil-Based Varnishes and Paints III. Photo- and Thermooxidation of Cured Linseed Oil. J. Am. Oil Chem. Soc. 2000, 77, 257-263.

(7) Lazzari, M.; Chiantore, O. Drying and Oxidative Degradation of Linseed Oil. Polym. Degrad. Stab. 1999, 65, 303-313.

(8) Van den Berg, J. D. J.; Van den Berg, K. J.; Boon, J. J. Determination of the Degree of Hydrolysis of Oil Paint Samples Using a Two-Step Derivatisation Method and on-Column GC/MS. Prog. Org. Coat. 2001, 41, 143-155.

(9) Van Dam, E. P.; Van den Berg, K. J.; Proaño Gaibor, A. N.; Van Bommel, M. Analysis of Triglyceride Degradation Products in Drying Oils and Oil Paints Using LC-ESI-MS. Int. J. Mass Spectrom. 2016, 1-10.

(10) Osmond, G.; Boon, J. J.; Puskar, L.; Drennan, J. Metal Stearate Distributions in Modern Artists' Oil Paints: Surface and Cross-Sectional Investigation of Reference Paint Films Using Conventional and Synchrotron Infrared Microspectroscopy. Appl. Spectrosc. 2012, 66, 1136-1144.

(11) loakimoglou, E.; Boyatzis, S.; Argitis, P.; Fostiridou, A.; Papapanagiotou, K.; Yannovits, N. Thin-Film Study on the Oxidation of Linseed Oil in the Presence of Selected Copper Pigments. Chem. Mater. 1999, 11, 2013-2022.

(12) Mazzeo, R.; Prati, S.; Quaranta, M.; Joseph, E.; Kendix, E.; Galeotti, M. Attenuated Total Reflection Micro FTIR Characterisation of Pigment-Binder Interaction in Reconstructed Paint Films. Anal. Bioanal. Chem. 2008, 392, 6576.

(13) Hermans, J.; Keune, K.; Van Loon, A.; Corkery, R. W.; ledema, P. lonomerlike Structure in Mature Oil Paint Binding Media. RSC Adv. 2016, 6, 9336393369.

(14) MacDonald, M. G.; Palmer, M. R.; Suchomel, M. R.; Berrie, B. H. Reaction of $\mathrm{Pb}$ (II) and $\mathrm{Zn}$ (II) with Ethyl Linoleate To Form Structured Hybrid InorganicOrganic Complexes: A Model for Degradation in Historic Paint Films. ACS Omega 2016, 1, 344-350.

(15) Rogge, C. E.; Arslanoglu, J. Distinguishing Manufacturing Practices for Titanium White Pigments: New Raman Markers for Dating Commercial OilBased Paints. Stud. Conserv. 2016, 61, 324-326. 
(16) Van Driel, B. A.; Wezendonk, T. A.; Van den Berg, K. J.; Kooyman, P. J.; Gascon, J.; Dik, J. Determination of Early Warning Signs for Photocatalytic Degradation of Titanium White Oil Paints by Means of Surface Analysis. Spectrochim. Acta, Part A 2016, 172, 100-108.

(17) Luttrell, T.; Halpegamage, S.; Tao, J.; Kramer, A.; Sutter, E.; Batzill, M. Why Is Anatase a Better Photocatalyst than Rutile? Model Studies on Epitaxial $\mathrm{TiO}_{2}$ Films. Sci. Rep. 2014, 4, 4043.

(18) Van Driel, B. A.; Kooyman, P. J.; Van den Berg, K. J.; Schmidt-Ott, A.; Dik, J. A Quick Assessment of the Photocatalytic Activity of $\mathrm{TiO}_{2}$ Pigments - From Lab to Conservation Studio! Microchem. J. 2016, 126, 162-171.

(19) Pappas, S. P.; Fischer, R. M. Photochemistry of Pigments. Studies on the Mechanism of Chalking. Pigm. Resin Technol. 1975, 4, 3-10.

(20) Lauridsen, C. B.; Sanyova, J.; Simonsen, K. P. Analytical Study of Modern Paint Layers on Metal Knight Shields: The Use and Effect of Titanium White. Spectrochim. Acta, Part A 2014, 124, 638-645.

(21) Dlugogorski, B. Z.; Kennedy, E. M.; Mackie, J. C. Low Temperature Oxidation of Linseed Oil: A Review. Fire Sci. Rev. 2012, 1, 3.

(22) Boon, J. J.; Keune, K.; Van der Weerd, J.; Geldof, M.; Van Asperen de Boer, J. R. J. Imaging Microspectroscopic, Secondary Ion Mass Spectrometric and Electron Microscopic Studies on Discoloured and Partially Discoloured Smalt in Cross- Sections of 16th Century Paintings. Chimica 2001, 55, 952-960.

(23) Keune, K.; Boon, J. J. Analytical Imaging Studies of Cross-Sections of Paintings Affected by Lead Soap Aggregate Formation. Stud. Conserv. 2007, 52, 161-176.

(24) Van Loon, A.; Boon, J. J. Characterization of the Deterioration of Bone Black in the 17th Century Oranjezaal Paintings Using Electron-Microscopic and Micro-Spectroscopic Imaging Techniques. Spectrochim. Acta, Part B 2004, 59, 1601-1609.

(25) Bhargava, R. Infrared Spectroscopic Imaging: The next Generation. Appl. Spectrosc. 2012, 66, 1091-1120.

(26) Dazzi, A.; Prater, C. B. AFM-IR: Technology and Applications in Nanoscale Infrared Spectroscopy and Chemical Imaging. Chem. Rev. 2016, DOI: acs.chemrev.6b00448.

(27) Morsch, S.; Lyon, S.; Smith, S. D.; Gibbon, S. R. Mapping Water Uptake in an Epoxy-Phenolic Coating. Prog. Org. Coat. 2015, 86, 173-180.

(28) Morsch, S.; Lyon, S.; Greensmith, P.; Smith, S. D.; Gibbon, S. R. Mapping Water Uptake in Organic Coatings Using AFM-IR. Faraday Discuss. 2015, 180, 527-542.

(29) Morsch, S.; Liu, Y.; Lyon, S. B.; Gibbon, S. R. Insights into Epoxy Network Nanostructural Heterogeneity Using AFM-IR. ACS Appl. Mater. Interfaces 2016, 8, 959-966.

(30) Lahiri, B.; Holland, G.; Centrone, A. Chemical Imaging Beyond the Diffraction Limit: Experimental Validation of the PTIR Technique. Small 2013, 9, 439445.

(31) Dazzi, A.; Glotin, F.; Carminati, R. Theory of Infrared Nanospectroscopy by Photothermal Induced Resonance. J. Appl. Phys. 2010, 107, 124519.

(32) Kjoller, K.; Felts, J. R.; Cook, D.; Prater, C. B.; King, W. P. High-Sensitivity Nanometer-Scale Infrared Spectroscopy Using a Contact Mode 
Microcantilever with an Internal Resonator Paddle. Nanotechnology 2010, 21, 185705.

(33) Deniset-Besseau, A.; Prater, C. B.; Virolle, M.-J.; Dazzi, A. Monitoring TriAcylGlycerols Accumulation by Atomic Force Microscopy Based Infrared Spectroscopy in Streptomyces Species for Biodiesel Applications. J. Phys. Chem. Lett. 2014, 5, 654-658.

(34) Mayet, C.; Dazzi, A.; Prazeres, R.; Ortega, J.-M.; Jaillard, D. In Situ Identification and Imaging of Bacterial Polymer Nanogranules by Infrared Nanospectroscopy. Analyst 2010, 135, 2540-2545.

(35) De Viguerie, L.; Payard, P. A.; Portero, E.; Walter, Ph.; Cotte, M. The Drying of Linseed Oil Investigated by Fourier Transform Infrared Spectroscopy: Historical Recipes and Influence of Lead Compounds. Prog. Org. Coat. 2016, 93, 46-60.

(36) Fjällström, P.; Andersson, B.; Nilsson, C.; Andersson, K. Drying of Linseed Oil Paints: A Laboratory Study of Aldehyde Emissions. Ind. Crops Prod. 2002, 16, 173-184.

(37) Zumbühl, S.; Scherrer, N. C.; Eggenberger, U. Derivatization Technique to Increase the Spectral Selectivity of Two-Dimensional Fourier Transform Infrared Focal Plane Array Imaging: Analysis of Binder Composition in Aged Oil and Tempera Paint. Appl. Spectrosc. 2014, 68, 458-465.

(38) Bonaduce, I.; Carlyle, L.; Colombini, M. P.; Duce, C.; Ferrari, C.; Ribechini, E.; Selleri, P.; Tiné, M. R. New Insights into the Ageing of Linseed Oil Paint Binder: A Qualitative and Quantitative Analytical Study. PLoS One 2012, 7, e49333.

(39) Gesenhues, U. Influence of Titanium Dioxide Pigments on the Photodegradation of Poly(vinyl Chloride). Polym. Degrad. Stab. 2000, 68, 185-196.

(40) Spathis, P.; Karagiannidou, E.; Magoula, A. Influence of Titanium Dioxide Pigments on the Photodegradation of Paraloid Acrylic Resin. Stud. Conserv. 2003, 48, 57-64.

(41) Allen, N. S.; Parker, M. J.; Regan, C. J.; Mclntyre, R. B.; Dunk, W. A. E. The Durability of Water-Borne Acrylic Coatings. Polym. Degrad. Stab. 1995, 47, 117-127.

(42) Melo, M. J.; Bracci, S.; Camaiti, M.; Chiantore, O.; Piacenti, F. Photodegradation of Acrylic Resins Used in the Conservation of Stone. Polym. Degrad. Stab. 1999, 66, 23-30.

(43) Liang, R. H.; Tsay, F.-D.; Gupta, A. Photodegradation of Poly (n-Butyl Acrylate). Photochemical Processes in Polymeric Systems. Macromolecules 1982, 15, 974-980.

(44) Grassie, N.; Speakman, J. G.; Davis, T. I. Thermal Degradation of Poly(alkyl Acrylates). II. Primary Esters: Ethyl, n-Propyl, n-Butyl, and 2-Ethylhexyl. J. Polym. Sci., Part A-1: Polym. Chem. 1971, 9, 931-948.

(45) Lin-Vien, D.; Colthup, N. B.; Fateley, W. G.; Grasselli, J. G. The Handbook of Infrared and Raman Characteristic Frequencies of Organic Molecules; Academic Press Ltd: London, 1991.

(46) Hill, G. A.; Rice, J. H.; Meech, S. R.; Craig, D. Q. M.; Kuo, P.; Vodopyanov, K.; Reading, M. Submicrometer Infrared Surface Imaging Using a ScanningProbe Microscope and an Optical Parametric Oscillator Laser. Opt. Lett. 2009, 34, 431-433. 
(47) Hoffmann, U.; Pfeifer, F.; Hsuing, C.; Siesler, H. W. Spectra Transfer Between a Fourier Transform Near-Infrared Laboratory and a Miniaturized Handheld Near-Infrared Spectrometer. Appl. Spectrosc. 2016, 70, 852-860.

(48) Ormsby, B.; Learner, T.; Schilling, M.; Druzik, J.; Khanjian, H.; Carson, D.; Foster, G.; Sloan, M. The Effects of Surface Cleaning on Acrylic Emulsion Paintings: A Preliminary Investigation. Tate Papers 2006, 6, 1-14. 


\section{TOC Graphic}
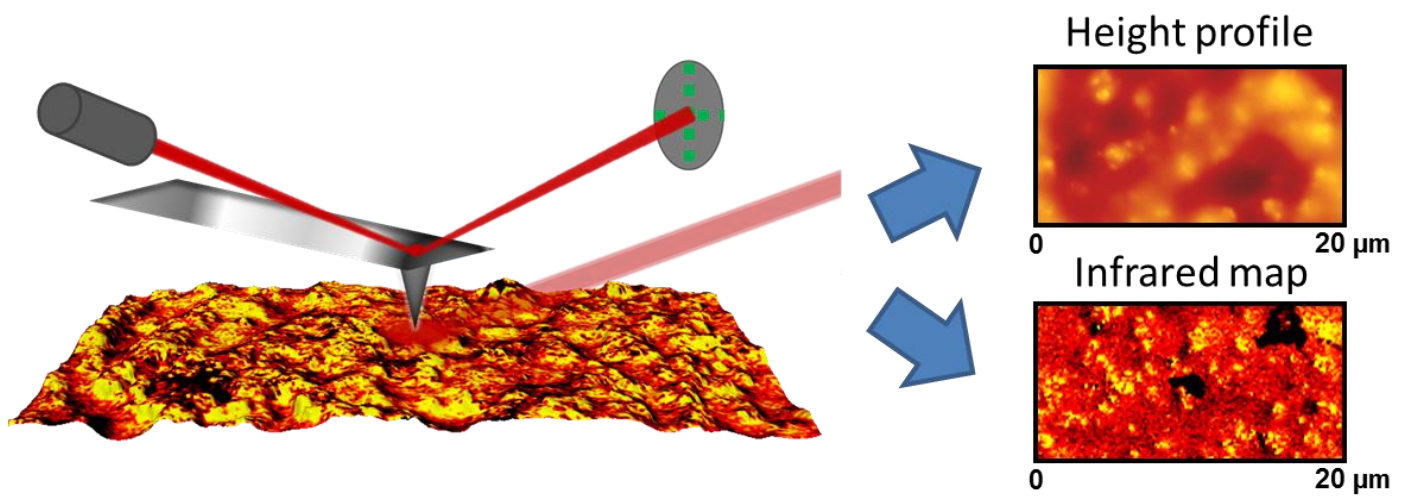